\title{
PREMATURE EPIPHYSIAL FUSION AT THE KNEE COMPLICATING PROLONGED IMMOBILISATION FOR CONGENITAL DISLOCATION OF THE HIP
}

\author{
T. D. J. Botting and W. H. Scrase, Birmingham, England \\ From the Royal Orthopaedic Hospital, Birmingham
}

Gill (1944) first showed that shortening of a limb affected by tuberculous disease of the hip could be caused by premature fusion of the epiphyses of the knee. Jones (1899) estimated the frequency of such shortening at about 15 per cent. It is now established that premature epiphysial arrest at the knee may complicate prolonged immobilisation for many other hip conditions such as pyogenic arthritis, chronic osteomyelitis and slipped upper femoral epiphysis (Ross 1948). Kestler (1947) described a case of premature epiphysial arrest in association with congenital dislocation of the hip and we wish to record three further cases.

\section{CASE REPORTS}

Case 1-A girl of nearly four was found to have congenital dislocation of the right hip. She was treated on a Robert Jones abduction frame for six months, and thereafter in a bilateral plaster-of-Paris hip spica in the "frog" position for

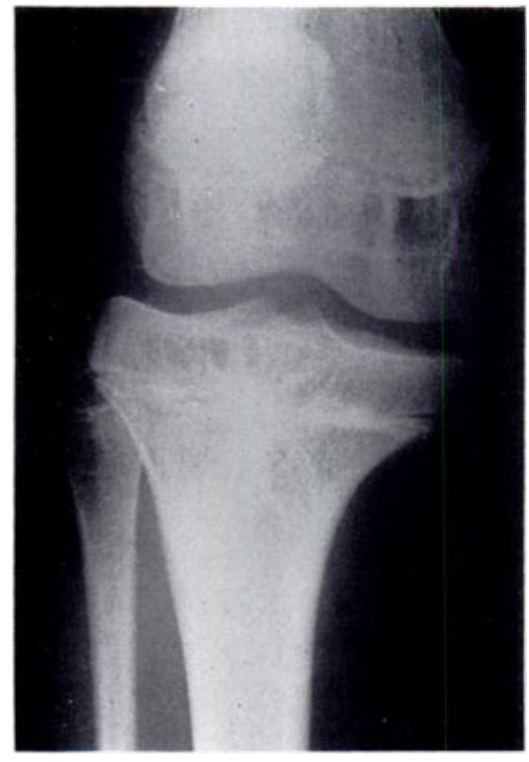

FIG. 1

Case 1-Showing premature fusion of the upper tibial epiphysis on the right side. eleven months, after which she was allowed free. Eight months later, because of a persistent 90 degrees lateral rotation and 30 degrees flexion deformity of the affected hip, Pugh traction was applied followed by serial broomstick plasters for two months. Thereafter full movements were rapidly regained and a stable reduction was maintained. The total period of immobilisation was nineteen months.

When she was seven, half an inch of shortening of the right lower limb was noted, and this increased by about half an inch a year until she was thirteen when the limb was three inches short. Radiographs showed reduction of the right hip and slight coxa vara and protrusion acetabuli which were insufficient to account for all the shortening. The right knee showed premature closure (Matthiesen 1957) of the upper tibial epiphysis (Fig. 1).

Case 2-A girl of fifteen months was found to have bilateral congenital dislocation of the hips. She was treated by reduction on a Robert Jones abduction frame followed by a bilateral plaster-of-Paris hip spica in the "frog " position for twelve months, after which the hips were stable. When she was six it was noticed that the right hip was subluxating and that the left lower limb was half an inch shorter than the right. This shortening gradually increased until the left lower limb was two and a half inches short and there was tibia vara and prominence of the fibular heads (Fig. 2).

Radiographs showed redislocation of the right hip. There was premature closure of the lower femoral and upper tibial epiphysis on the left side, and of the upper tibial epiphysis on the right (Fig. 3).

The serum chemistry was normal. Excision of the fibular heads, elongation of the left tibia and stabilisation of the right hip is now planned for her. 


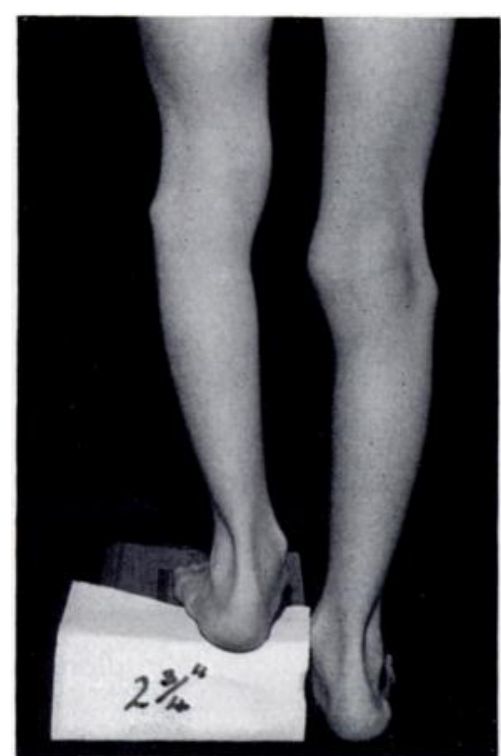

Fig. 2

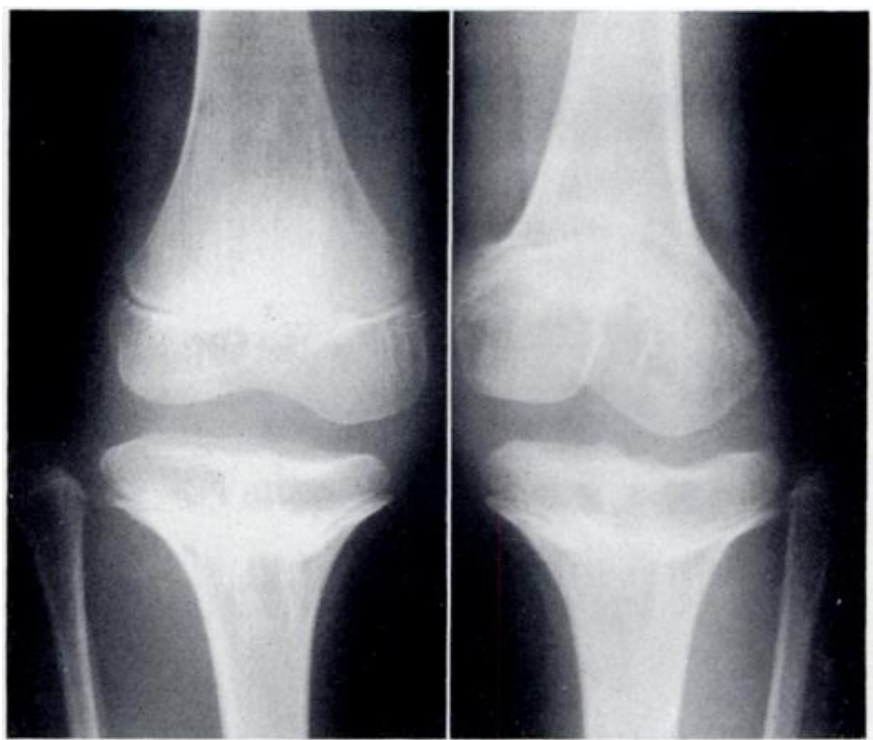

FIG. 3

Case 2. Figure 2-Showing the shortening, the degree of tibia vara and the prominence of the fibular heads. Figure 3-Showing premature fusion of the lower femoral and upper tibial epiphyses on the lett side and of the upper tibial epiphysis on the right.

Case 3-A girl of two and a half was found to have a congenital dislocation of the left hip and subluxation of the right. She was treated by reduction on a Robert Jones abduction frame followed by a bilateral plaster-of-Paris hip spica in the "frog" position for sixteen months, after which she was allowed free. When she was nine, one inch of shortening of the left lower limb was noted and radiographs showed subluxation of the left hip and premature epiphysial fusion of the left upper tibial epiphysis (Fig. 4). The shortening gradually increased, and when she was fifteen the limb was two and a half inches short.

\section{DISCUSSION}

Premature epiphysial fusion at the knee in such instances is difficult to explain. The theory of Gill (1944) elaborated by Ross (1948) suggested thinning of the epiphysial plate and weakening of the bony trabecular support due to disuse atrophy, toxic depression of osteogenesis, and osteoporosis. Minor trauma may then cause rupture of the epiphysial plate and a bony bridge across the epiphysis. This theory is only concerned with inflammatory hip disease.

Kestler (1947) suggested that epiphysial arrest occurred as a result of diminished blood supply to the epiphysial plate. But this was discounted by Parke, Colvin and Almond (1949); and Sissons (1952) failed to show any histological evidence of impaired blood supply in eight cases.

Troupp (1961) showed that in rabbits devascularisation of the hind limbs produced changes in the knee epiphyses identical with those described by Matthiesen (1957) in humans. The more distal epiphysis, which suffered relatively greater ischaemia, was affected first. Experimental interruption of the epiphysial or metaphysial blood supply to the epiphysial plate has produced

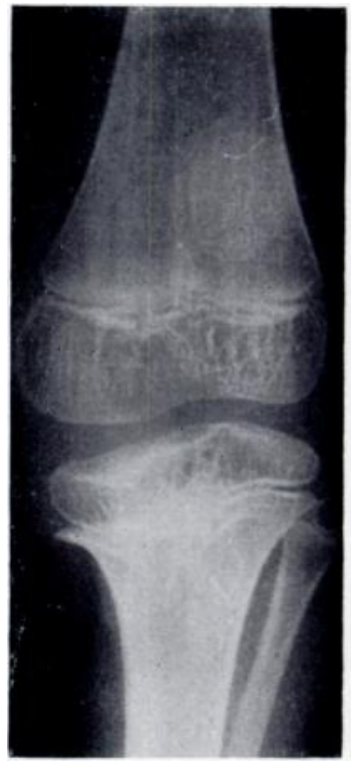

Fig. 4

Case 3-Showing premature fusion of the left upper tibial epiphysis. 
similar changes with, in many cases, complete epiphysiodesis (Trueta and Amato 1960). Although ischaemia explains epiphysial arrest in the absence of trauma or toxic effect and the more usual involvement of the upper tibial epiphysis, the reason for involvement of only the ipsilateral knee is not known.

It is known that blood flow in a limb is reduced by fixation in plaster-of-Paris (Hultén 1951), and it has been shown that traction on a limb produces arterial spasm (Mustard and Simmons 1953). Nicholson, Kopell and Mattei (1954) in injection experiments on cadavers showed that in the "frog" position the profunda femoris and medial circumflex arteries failed to fill. The combination of plaster fixation, traction and the "frog" position may therefore produce a marked diminution of blood flow in the lower limbs. Ischaemic changes in the upper femoral epiphysis complicating conservative treatment of congenital dislocation of the hip are not rare: Mackenzie, Seddon and Trevor (1960) showed an incidence of about 20 per cent.

\section{SUMMARY}

1. Three cases of premature epiphysial closure at the knee complicating prolonged immobilisation for congenital dislocation of the hip are described.

2. The etiology of this complication is briefly discussed, and it is suggested that relative ischaemia of the epiphysial plates is the most likely cause.

\section{REFERENCES}

Gill, G. G. (1944): The Cause of Discrepancy in Length of the Limbs Following Tuberculosis of the Hip in Children. Journal of Bone and Joint Surgery, 26, 272.

Hultén, O. (1951): The Influence of a Fixation Bandage on the Peripheral Blood Vessels and the Circulation. Acta Chirurgica Scandinavica, 101, 151.

Jones, R. (1899): On Prevention of Short Leg in Hip Disease. John Bale \& Sons Danielson Ltd.

KestleR, O. C. (1947): Unclassified Premature Cessation of Epiphyseal Growth About the Knee Joint. Journal of Bone and Joint Surgery, 29, 788.

Mackenzie, I. G., Seddon, H. J., and Trevor, D. (1960): Congenital Dislocation of the Hip. Journal of Bone and Joint Surgery, 42-B, 689.

Matthiesen, D. E. (1957): Premature Growth Arrest of the Knee Epiphyses. American Journal of Roentgenology, Radium Therapy and Nuclear Medicine, 78, 499.

Mustard, W. T., and Simmons, E. H. (1953): Experimental Arterial Spasm in the Lower Extremities Produced by Traction. Journal of Bone and Joint Surgery, 35-B, 437.

Nicholson, J. T., Kopell, H. P., and Mattei, F. A. (1954): Regional Stress Angiography of the Hip. Journal of Bone and Joint Surgery, 36-A, 503.

Parke, W., Colvin, G. S., and Almond, A. H. G. (1949): Premature Epiphysial Fusion at the Knee Joint in Tuberculous Disease of the Hip. Journal of Bone and Joint Surgery, 31-B, 63.

Ross, D. (1948): Disturbance of Longitudinal Growth Associated with Prolonged Disability of the Lower Extremity. Journal of Bone and Joint Surgery, 30-A, 103.

Sissons, H. A. (1952): Osteoporosis and Epiphysial Arrest in Joint Tuberculosis. Journal of Bone and Joint Surgery, 34-B, 275.

Troupp, H. (1961): Nervous and Vascular Influence on Longitudinal Growth of Bone. Acta Orthopaedica Scandinavica, Supplementum 51.

Trueta, J., and Amato, V. P. (1960): The Vascular Contribution to Osteogenesis. III. Changes in the Growth Cartilage Caused by Experimentally Induced Ischaemia. Journal of Bone and Joint Surgery, 42-B, 571. 